\title{
APUESTAS EDUCATIVAS EN MOMENTOS DE TRANSICIÓN HACIA LA PAZ
}

\author{
EDUCATIONAL BETTING IN PEACE TRANSITION TIMES
}

APOSTAS EDUCACIONAIS EM TEMPOS DE TRANSIÇÃO PARA A PAZ

\section{Tany Giselle Fernández Guayana ${ }^{1}$}

1CCorporación Universitaria Minuto de Dios, Colombia, tany.fernandez.g@uniminuto.edu.co; tany.fernandezg@gmail.com

Fecha de recepción: 26 de febrero de 2021

Fecha de aceptación: 26 de abril de 2021

\section{RESUMEN}

El actual ensayo presenta una reflexión crítica en torno a las apuestas educativas necesarias para los momentos de transición hacia la paz por los cuales está pasando Colombia. El posconflicto supone hoy una demanda educativa que requiere de respuesta por parte de los formadores y agentes educativos. En razón de ello, el país tiene como tarea trazar nuevos horizontes de sentido, tomando como base, aquellas apuestas que han logrado instaurar políticamente desde la educación pero que, en medio de los constantes cambios sociales, requieren de mayor atención: los ambientes educativos, el currículo y la cátedra de la paz. No obstante, se hace necesario como elemento transversal, establecer lazos sinérgicos entre los demás agentes que rodean la niñez y la juventud a fin de trascender el escenario de la escuela y, por tanto, la labor formativa de los colombianos. Es así como se concluye que, en momentos de transición, todo acto educativo debe propender al emprendimiento, a la explotación de la creatividad, a nuevas formas de interacción, al establecimiento de espacios dialógicos, al tejido de las subjetividades, a la configuración de colectivos y, por tanto, al rescate de lo humano.

Palabras Claves: transición, paz, ambiente educacional, currículo, cátedra de la paz.

\begin{abstract}
This essay presents a critical reflection on necesity educational bets for Colombia's peace transition. The postconflict is today an educational demand that requires a response from the trainers and educational agents. As a result, the country has the task of drawing new horizons of meaning, based on the bets that it has managed to establish politically from education. But in the midst of constant social changes, those bets require more attention: educational environment, the Curriculum and the peace subject. However, it is necessary as a transversal element, to establish synergistic ties between the other agents that surround children and youth. This allows transcend the schol stage and therefore, the formative work of the Colombians that we wish to be. To sum up, in peace transition, every educational act should tend to entrepreneurship, to explote of creativity, to create new ways of interaction, to establish dialogic spaces, to fabric of subjectivities, to configurate the collective and, therefore, to rescue the human being.
\end{abstract}

Key words: transition, peace, educational environment, Curriculum, peace cathedra.

30 Apuestas educativas en momentos de transición hacia la paz 


\section{RESUMO}

O presente artigo apresenta uma reflexão crítica sobre as apostas educacionais necessárias para os momentos de transição pelos quais a Colômbia está passando. O pós-conflito é hoje uma demanda educacional que requer uma resposta dos treinadores e agentes educacionais. Como resultado, o país tem a tarefa de traçar novos horizontes de significado, com base nas apostas que conseguiu estabelecer politicamente a partir da educação, mas, em meio a constantes mudanças sociais, exige mais atenção: ambientes educacionais, currículo o cadeira da paz. Porém, é necessário, como elemento transversal, estabelecer vínculos sinérgicos entre os demais agentes que cercam crianças e jovens, a fim de transcender o cenário da escola e, portanto, o trabalho formativo dos colombianos que desejamos ser. Conclui-sé que, em momentos de transição, todo ato educativo deve tender ao empreendedorismo, à exploração da criatividade, novas formas de interação, estabelecimento de espaços dialógicos, tecido de subjetividades, configuração coletiva e, portanto, para o resgate do humano.

Palavras chaves: transição, paz, ambiente educacional, currículo, cadeira da paz

\section{1.- INTRODUCCION}

Posconflicto es tal vez, la palabra que más se ha escuchado y pronunciado en Colombia los últimos años. Y no es para menos. Luego de un periodo aproximado de cinco décadas en violencia a causa del conflicto armado (Chaux y Velásquez, 2016), presentar firmado un tratado de paz (23 de septiembre de 2016), se torna como aquel hondo sueño que una vez, al abrir los ojos, se vuelve realidad. Sin embargo, no es de desconocimiento para nadie, que unas personas en paz, que un ambiente de paz, que un país en paz, requieren de un proceso. Por consiguiente, en estos momentos de transición, Colombia demanda por nuevos espacios para la convivencia a partir de la sinergia entre todos los actores, instituciones y personas que hacen parte del país (Salamanca, Rodríguez, Cruz, Ovalle, Pulido y Molano, 2016). En vista de la relevancia histórica que tiene tal acontecimiento, se hace necesario que, los ambientes donde se desenvuelven los niños, niñas y jóvenes se transformen, se cambien y se modifiquen trascendiendo el escenario de la escuela con el fin de lograr "una paz sostenible" (Chaux y Velásquez, 2016, p.9).

De hecho, se han realizado esfuerzos constantes por adaptar el currículo a la idiosincrasia y contexto colombiano dejando de lado la importación de teorías extranjeras que hacen del contexto, una realidad lejana para la infancia y la juventud (Pineda y Loaiza, 2017).
El currículo demanda hoy de la flexibilidad para adaptarse a los cambios a nivel social, educativo, político y económico a fin de proteger y consolidar el capital cultural. Así, el currículo puede propender a la construcción de otras formas de habitar a partir de valoración de la diferencia, el reconocimiento del Otro y la re-dignificación de los niños, niñas y jóvenes víctimas y participantes del conflicto armado.

Por su parte, el Ministerio de Educación, se ha enfocado en la creación e implementación de la «cátedra de la paz», iniciativa establecida a partir de la Ley 1732 de 2014, Decreto 1038 de 2015, donde, las instituciones educativas como carácter obligatorio, deben incluirla en sus planes de estudios. Con esta propuesta se pretende "crear y consolidar un espacio para el aprendizaje, la reflexión y el diálogo sobre la cultura de la paz y el desarrollo sostenible" (Ley 1732, Parágrafo 2). No obstante, trabajar esta propuesta como una asignatura más del plan de estudios, se queda insuficiente ante la demanda de un país en construcción hacia la paz (Salamanca, Rodríguez, Cruz, Ovalle, Pulido y Molano, 2016).

La responsabilidad aquí no sólo recae en la educación formal, ya que, la infancia y la juventud están rodeadas de múltiples escenarios que influyen en la configuración de su identidad, en el tejido de sus subjetividades, en el afianzamiento de sus cosmovisiones y en sus for- 
mas de actuar. En este sentido, el objetivo de este artículo consiste en propiciar un espacio reflexivo sobre los recursos educativos con los que cuentan los colombianos para asumir con sus niños, niñas y jóvenes la etapa del posconflicto y por lo tanto, la reconstrucción de la nación.

\section{2.- APUESTAS DESDE LOS AMBIENTES EDUCA- TIVOS}

La escuela ha sido concebida el ambiente propicio para el aprendizaje, sin embargo, en estos momentos de transición para Colombia, es insuficiente. De modo que, la escuela requiere de una alianza con los demás agentes que rodean a los niños, niñas y jóvenes, ya que, en medio de las relaciones que surgen entre cada uno de ellos, se posibilita el intercambio de intereses, la definición de objetivos colectivos y el establecimiento de acciones que le transformen y transforme (Ospina, 1999; Moreno y Molina, 1993). Asímismo, un ambiente educativo en sinergia posibilita a los futuros ciudadanos transformar su realidad generando una actitud de emprendimiento y explotación de su creatividad.

Un futuro mejor, un país mejor, un ambiente en paz, requiere del trabajo de todos, de la capacidad de poder ver en los otros su demanda, de la cual no pueden extraerse (Lévinas, 2014); por lo tanto, se debe estar preparado para responder a éste en cualquier ambiente. El ser humano desde que nace está sumergido en distintos medios y por supuesto, la escuela hace parte del principal sistema relacional (Bronfenbrenner, 2002). Empero, así como se menciona en la Teoría Ecológica del Desarrollo, el individuo, quien está en el centro, es influenciado por los demás sistemas que lo rodean y a su vez, éste los influye también (Ver Figura 1):

Figura 1. Cinco sistemas de la Teoría Ecológica de Bronfenbrenner

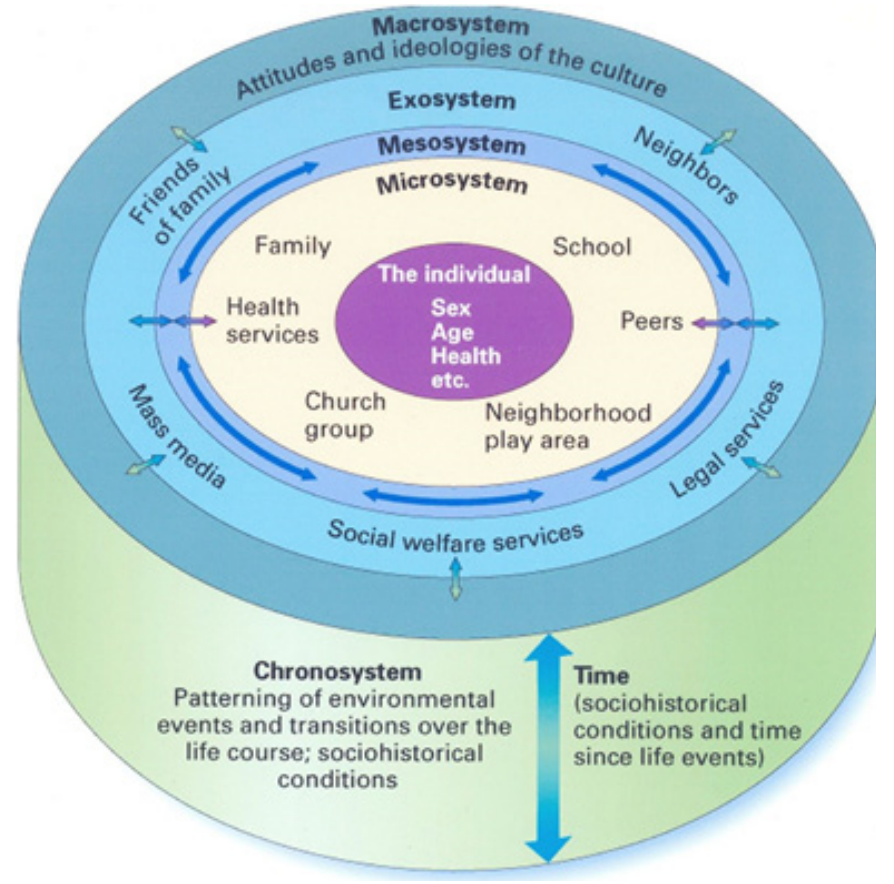

Fuente: Bronfenbrenner U. (2002). La ecología del desarrollo humano 
Con lo anterior, no se quiere profundizar desde el campo psicológico la afectación que surge en el sujeto a partir de los distintos sistemas, por el contrario, se desea afirmar la importancia de los diversos ambientes donde se desenvuelve la persona, porque al final, todo sistema, escenario y lugar proporcionan un espacio de encuentro consigo mismo, con el Otro, con los Otros y con lo Otro. De manera que, para la transición por la cual está atravesando Colombia, se hace imprescindible modificar cada uno de los ambientes, no sólo en sus condiciones físicas, sino en los modos de interacción.

Según Ospina (1999), un ambiente educativo es:

"El lugar en donde confluyen diferentes actores para interactuar con relación a ciertos aspectos, situaciones, contenidos, utilizando para ello métodos y técnicas previamente establecidos con la intención de adquirir conocimientos, desarrollar habilidades, actitudes y en general, desarrollar algún tipo de capacidad o competencia” (p.5).

Así, el ambiente educativo se torna en un espacio de constante intencionalidad que posibilita la comunicación y el encuentro, "da lugar a materiales y actividades, a la capacidad creadora y el diálogo, a fin de que se permita la expresión libre de las ideas, intereses, necesidades y estados de ánimo" (Duarte, 2003, p.8). Hacer conciencia sobre el contexto y el devenir histórico de los colombianos, así como considerar el ambiente educativo un lugar de interacción y no sólo de desplazamiento, propicia el desarrollo del ser, sentirse arraigado a sí mismo y al territorio, construyendo escenarios colectivos significativos (Duarte, 2003).

Según Santos (2006) en todo ambiente educativo existen un conjunto de valores, actitudes y juicios que imperan en el sistema. Esas prácticas, no siempre establecidas formalmente son las que impactan en la comunidad, porque, a la larga, al momento de reconstruir un país para la paz entra "en juego una forma de sensi- bilidad porque no se trata de la experiencia individual, sino de la afección que se comparte con el grupo y que decide el curso del comportamiento del sujeto y su escena en público" (Duarte, 2013, p.13)

Es a partir del conocimiento de las realidades que se viven y de las propias expresiones simbólicas, que se encuentran las posibilidades de acción y de la reconstrucción del discurso. Al brindar una oportunidad a la infancia y a la juventud en el ejercicio de su autonomía y el despliegue de la conciencia contextual, "se crean oportunidades y condiciones para que ellos puedan reconocerse como protagonistas de su propia historia capaces de interactuar con otros en la construcción de proyectos colectivos, con espíritu crítico y capacidad de apropiación de los significados culturales" (Alvarado, Ospina, Botero, Muñoz, 2009, p.13). Gracias a ello, se promueven otras formas de "compartir el poder" (Cubides, 2004, p.122) donde el diálogo en un espacio común, y sin importar las diferencias generacionales, permite en las futuras poblaciones la configuración de la ciudadanía y de su subjetividad política.

Un ambiente educativo se convierte entonces en una realidad donde los individuos se hacen y se muestran, cuyas relaciones con el medio y con los demás permite el intercambio permanente. Es por esa razón que, se hace difícil escoger un sólo ambiente como el más propicio para fomentar el aprendizaje de una cultura de la paz en los niños, niñas y jóvenes. Todos los ambientes a los cuales pertenece el sujeto le afectan y le posibilitan construir sentidos en las realidades por medio del intercambio dialógico y el encuentro con el otro. De esa forma, se llega a la conclusión de que un ambiente educativo es también un proyecto ético, y como tal, transciende las esferas de la educación formal respondiendo a las necesidades humanas, en el caso colombiano: a la paz.

\section{3.- APUESTAS DESDE EL CURRÍCULO}

En estos tiempos álgidos, pero a la vez esperanzadores, 
es imprescindible preguntarse cuál es el aporte que espera la sociedad colombiana desde el currículum escolar en los procesos de postconflicto. Si bien el currículo es aquella construcción que responde a la pregunta “¿qué se debe enseñar?” (Kemmis, 1998), es importante que los agentes educativos centren su atención en la búsqueda de una autonomía curricular que atienda a las nuevas demandas sociales del país.

Según Pineda y Loaiza (2017), desde 1960 hasta 1994, la educación en Colombia ha dependido de currículos extranjeros. Así sucedió con la Misión Pedagógica Alemana la cual buscó erradicar el analfabetismo y el ausentismo escolar, aumentar el profesionalismo y mejorar la calidad educativa. De igual forma ocurrió con la importación del currículo de la Organización de los Estados Americano (OEA) con el propósito de hacer una reforma técnico-instrumental. Si bien sus aportes tuvieron impactos en la transformación de la educación a la era moderna, el país, sufrió influencias hegemónicas por las ideologías que traían consigo estos vínculos extranjeros (Pineda y Loaiza, 2017).

Al importar currículos de otros países, se corre con el riesgo de homogeneizar a una población. Se deja de lado el capital cultural de cada territorio imponiendo una serie de normativas sin tener en cuenta la idiosincrasia ni las verdaderas necesidades de la comunidad "en cuanto a comportamientos, habilidades y destrezas, sin fundamentos culturales y políticos" (Pineda y Loaiza, 2017, p.165). Por lo tanto, el currículo importado puede ejercer algunos mecanismos de control y la anulación del Otro: un distinto. Al respecto, Apple (1990) expresa que el currículo requiere vinculación del escenario político y económico con la escuela, pero centrarse en esas únicas miradas, colocaría en riesgo el capital humano y cultural de un país.

Desde el año 1994 hasta el día de hoy, en Colombia rige la Ley General de Educación (Ley 115) donde se estipula que el currículo "es el conjunto de criterios, planes de estudio, programas, metodologías y procesos que contribuyen a la formación integral y a la construcción de la identidad cultural... incluyendo los recursos humanos, académicos y físicos para poner en práctica las políticas y llevar a cabo el proyecto educativo institucional" (Artículo 76). Con ello, el currículo pasa de ser un plan de estudios como se estipulaba en las teorías tradicionalistas, a ser un compendio que compromete las experiencias, los saberes, las formas y los sujetos implicados en todo el acto educativo. De esta manera, el currículo colombiano toma por fin un rumbo autónomo.

A su vez, en el Artículo 77 de la misma Ley (Ley 115 de 1994), se especifica que "Dentro de los límites fijados... las instituciones de educación formal gozan de autonomía para organizar las áreas fundamentales de conocimientos definidas para cada nivel, introducir asignaturas optativas dentro de las áreas establecidas en la ley, adaptar algunas áreas a las necesidades y características regionales, adoptar métodos de enseñanza y organizar actividades formativas, culturales y deportivas.... Aquí entonces la apertura y la flexibilidad del currículo cobran protagonismo. En la medida que el currículo se adecue a las necesidades de cada institución y de cada comunidad, realista y oportuna será su intervención. En consecuencia, se podría afirmar que, en la sociedad colombiana, el currículo es apto y pertinente para los niños, niñas y jóvenes dado su carácter contextualizado.

Ahora bien, en el Artículo 78 de la mencionada Ley (Ley 115 de 1994), se aclara que el Ministerio de Educación Nacional es el encargado de diseñar los lineamientos generales de los procesos curriculares, aspecto que deja en vilo la autonomía de los establecimientos educativos. Toda institución deberá regirse bajo los parámetros expuestos por el Ministerio. En razón de ello, la autonomía curricular pasa a ser una utopía, porque, a pesar de que no se importen currículos extranjeros, son ahora los intereses de otros campos - distintos al formativo- los que están direccionando qué tipo de ciudadano se quiere tener.

Dado lo anterior, vale la pena preguntarse ¿en qué mo- 
mento se están reconociendo a los niños, niñas y jóvenes que han sido víctimas del conflicto y que se han desmovilizado?, ¿el currículo de las instituciones educativas colombianas está adaptado para que la comunidad educativa sea capaz de aceptar su reivindicación? Allí, es donde surge la tensión entre lo que realmente importa enseñar, lo que necesita la sociedad colombiana hoy y los intereses del sistema.

A pesar que la Ley General de Educación brinda libertad a al establecimiento del currículo según las necesidades y características regionales, lamentablemente, las instituciones educativas públicas y privadas se ven coartadas en sus idearios. Al final, deben responder a las exigencias y propósitos del sistema para ser bien evaluadas. Este es el caso de las pruebas estandarizadas. Colombia cuenta con sus propias pruebas: las pruebas $\mathrm{SABER}^{1}$, que, aunque son elaboradas bajo su contexto, no dejan de ser homogeneizadoras: ¿Cómo se les exige el mismo rendimiento a los estudiantes de zona urbana y a los niños, niñas y jóvenes que han vivido parte de sus años bajo el conflicto armado? Un currículo orientado hacia la paz no escatima según el color de piel, la edad, ni los antecedentes; por el contrario, es adaptado a la realidad y particularidad de cada estudiante logrando así un fin común, en este caso: la paz. Ahora bien, por si fuera poco, a las instituciones también se les exige destacarse en el mercado globalizado con los exámenes internacionales como las pruebas PISA, TIMMS y SERCE que, en su mayoría de ítems, no se adaptan a los conocimientos, experiencias, idiosincrasias, ni al contexto cultural de cada región.

En consecuencia, se hace necesario cuestionarse ¿qué debe enseñarse en momentos de transición hacia la paz? porque, a pesar de que cada establecimiento educativo presenta cierta autonomía curricular, hace falta que todo un país una sus fuerzas para centrar sus

\footnotetext{
${ }^{1}$ Son evaluaciones externas estandarizadas aplicadas por el Instituto Colombiano para la Evaluación de la Educación -ICFES-, las cuales evalúan el desempeño alcanzado por los estudiantes según las competencias básicas definidas por el Ministerio de Educación Nacional (Ministerio de Educación Nacional, 2020)
}

35 Apuestas educativas en momentos de transición hacia la paz ideales en lo que verdaderamente requiere la sociedad colombiana hoy. El país solicita entonces de un diálogo entre los curricula ${ }^{2}$ en los cuales se ven inmersas las futuras generaciones. Es decir, establecer en los documentos institucionales y nacionales las finalidades, contenidos y acciones de una cultura de la paz (currículo formal); poner en práctica lo establecido formalmente y evaluar lo vivido (currículo real); identificar aquello que no propende por la paz y que puede pasar desapercibido (currículo oculto); y propiciar experiencias de construcción de la paz fuera del ámbito educativo formal (currículo adicional) (Casarini, 2019). Hoy Colombia demanda de un currículo por la inclusión, por la comprensión, por la solidaridad, por la seguridad, por la participación y por el reconocimiento de los niños, niñas y jóvenes víctimas y participantes del conflicto armado. Así, el currículo posibilitará la plena transformación de sus ciudadanos, brindándoles la posibilidad de reconstruir y habitar el territorio común en paz.

\section{4.- APUESTAS DESDE LA CÁTEDRA DE LA PAZ}

Ante las demandas del posconflicto que ha presentado Colombia en los últimos años, se hace necesario "crear y consolidar un espacio para el aprendizaje, la reflexión y el diálogo sobre la cultura de la paz y el desarrollo sostenible" (Ley 1732, Parágrafo 2). De esta manera se garantiza que las futuras generaciones cuenten con las habilidades, aptitudes y recursos que les permitan convivir en medio de la diferencia, disminuyendo las brechas de orden económico y social. Por ello, a partir de la Ley 1732, Decreto 1038 de 2015, se establece como de obligatorio cumplimiento para las instituciones educativas colombianas, incluir en el plan de estudios la «cátedra de la paz».

Como ejemplo de la acogida de esta propuesta en las instituciones educativas colombianas, se expone un caso de una educadora de preescolar quien expresa

\footnotetext{
${ }^{2}$ Plural de currículo en latín
} 
con ensueño y a su vez, con algo de frustración, la realidad frente a la cátedra de la paz en el colegio donde laboraba. Veamos:

"En el mismo año que se instaura la cátedra de la paz [2015], tuve la oportunidad de trabajar como profesora del grado Transición ${ }^{3}$ en un colegio privado de la ciudad de Bogotá. Sabiendo la situación por la cual estaba pasando Colombia, dada las conversaciones por el acuerdo de paz entre el Gobierno Nacional y las FARC-EP4, coge mayor relevancia $y$ necesidad este tema en las aulas de clase. Lamentablemente, la realidad de una institución educativa limita los fines y funciones a las cuáles está llamada. Recuerdo bien que, al asignar la cátedra, nos reunieron a todos los profesores y de manera aleatoria, como si se tratase de un sorteo, se escoge qué docente va a hacerse cargo de esta cátedra. Y, por si fuera poco, para mi total decepción, con el tiempo, me di cuenta de cómo se estaba impartiendo y qué temas se abordaban... la cátedra de la paz que recibían mis estudiantes de Transición parecía una clase exclusivamente de valores"

Fuente: citación narrativa: (Fernández, comunicación personal, 17 de mayo de 2019)

${ }^{3}$ Según la Ley 115 de 1994 El nivel de educación preescolar en Colombia está integrado por tres grados (Prejardín, Jardín y Transición). Solo el de Transición es de prestación obligatoria, preferentemente debe ser a los cinco años. Por su parte, el Decreto 2247 de 1997 establece la denominación de Grado Transición en vez de Grado Cero. El propósito del Grado Transición consiste en preparar a los niños y las niñas para la escolarización formal y acompañar la transición que experimentan del hogar a los primeros grados de escolarización (Gaitán, 2018).

${ }^{4}$ Farc es el acrónimo de Fuerzas Armadas Revolucionarias de Colombia - Ejército del Pueblo. Fue una organización guerrillera insurgente y terrorista colombiana de izquierda, basada en la ideología y los principios del marxismo-leninismo (Castrillón y Cadavid, 2018; Zinecker, 2013)

36 Apuestas educativas en momentos de transición hacia la paz
El caso anterior, es ejemplo de lo que habitualmente ocurre con la cátedra de la paz en algunas aulas y centros educativos. Hay que recordar que según la Ley General de Educación (Ley 115 de 1994) se establece que cada institución tiene la autonomía curricular “...para organizar las áreas fundamentales de conocimientos definidas para cada nivel, introducir asignaturas optativas dentro de las áreas establecidas en la ley, adaptar algunas áreas a las necesidades y características regionales, adoptar métodos de enseñanza y organizar actividades formativas, culturales y deportivas..." (Artículo 77). De esta manera, la cátedra de la paz puede incluirse como asignatura, área del plan de estudios, programa o proyecto educativo.

Ahora bien, de acuerdo con el Decreto Reglamentario 1038 de 2015 por el cual se reglamenta la cátedra de la paz, los temas que se deben abordar son los siguientes (Ver Tabla 1): 
Tabla1. Temas relacionados con la Educación para la Paz

\begin{tabular}{|l|l|}
\hline Categorías de Educación para la Paz & \multicolumn{1}{|c|}{ Temas del Decreto Reglamentario 1038 } \\
\hline \multirow{2}{*}{ Convivencia Pacífica } & Resolución pacífica de conflictos \\
\cline { 2 - 2 } & Prevención del acoso escolar \\
\hline \multirow{2}{*}{ Participación ciudadana } & Participación política \\
\cline { 2 - 2 } & Proyectos de impacto social \\
\hline \multirow{2}{*}{ Diversidad e identidad } & Diversidad y pluralidad \\
\cline { 2 - 2 } & Protección de las riquezas culturales de la Nación \\
\hline \multirow{2}{*}{ Memoria histórica y reconciliación } & Memoria histórica \\
\cline { 2 - 2 } & $\begin{array}{l}\text { Historia de los acuerdos de paz nacionales e inter- } \\
\text { nacionales }\end{array}$ \\
\hline \multirow{2}{*}{ Desarrollo sostenible } & Uso sostenible de los recursos naturales \\
\cline { 2 - 2 } & Protección de las riquezas naturales de la Nación \\
\hline \multirow{2}{*}{ Ética, cuidado y decisiones } & Justicia y Derechos Humanos \\
\cline { 2 - 2 } & Dilemas morales \\
\cline { 2 - 2 } & Proyectos de vida y prevención de riesgos \\
\hline
\end{tabular}

Fuente: Ministerio Nacional de Colombia. (2016). Orientaciones generales para la implementación de la Cátedra de la Paz. En los establecimientos educativos de preescolar, básica y media de Colombia.

Dado lo anterior, el caso enfatiza en la importancia de contar con personal o un educador capacitado para la planeación, orientación e implementación de la cátedra de la paz. Las humanidades en torno a los temas de paz y de convivencia no se reducen a los valores humanos, también abarcan los conflictos inherentes a las relaciones humanas, el conocimiento y vivencia de los Derechos Humanos, la participación en procesos democráticos, la movilización de los medios, la gestión pacífica, la resolución de conflictos, y la cooperación con el desarrollo sostenible y equitativo (Salamanca, Rodríguez, Cruz, Ovalle, Pulido y Molano (2016).

Por su parte, Salamanca, Rodríguez, Cruz, Ovalle, Pulido y Molano (2016), recomiendan una serie de pasos en el proceso de inclusión de la cátedra de la paz en los establecimientos educativos, puesto que, el esfuerzo del Estado colombiano a través de los diálogos y finalmente, la firma del acuerdo de paz el 26 de septiembre de 2016, requiere de una respuesta institucional a las exigencias que se establecen con esta apuesta educativa. Como primer paso, debe hacerse un recorrido histórico, pedagógico y cultural con el Comité de Conviven- cia Escolar y los órganos del Gobierno Escolar a fin de elaborar la propuesta de articulación de la cátedra de la paz. En segunda medida, se requiere discutir e integrar la propuesta concorde al plan de área, los estándares, las competencias, la intensidad horaria, su obligatoriedad y los mecanismos de integración a los programas y proyectos a los cuales se adscribe. En un tercer momento, se selecciona a un docente cualificado e idóneo de los saberes y competencias que se determinan en la cátedra de la paz y que garantice su plena ejecución y desarrollo. Como cuarto paso, se envía la propuesta al Consejo Directivo para su aprobación. Finalmente, se ejecuta la propuesta.

En este sentido, el caso expuesto, refleja las dificultades y la situación actual por la que pasan algunas instituciones a la hora de implementar la cátedra de la paz en sus currículos. Por lo tanto, se hace necesario repensar sus métodos y formas de vinculación, que ante las demandas actuales no son suficientes. La aplicación de la cátedra de la paz requiere de su total contextualización según el ambiente y vida cotidiana de los niños, niñas y jóvenes. Necesita del involucramiento de todos 
los actores y agentes educativos. Requiere además de su transversalización curricular. Y finalmente, debe propiciar el afianzamiento de subjetividades políticas. Es así como se sugiere, a continuación, una reestructuración filosófica y pedagógica de los lineamientos que rigen hoy esta propuesta educativa.

Una cátedra de la paz contextualizada hace referencia al acto de recuperar sujetos individuales, que, a su vez son plurales, y a la necesidad de adecuar las temáticas del syllabus acodes con la historia social, cultural, política y económica del espacio concreto donde se desenvuelven los estudiantes. De acuerdo con Berger, Luckman (1995) y Zemelman (2004) socialmente existe una exigencia por recuperar sujetos capaces de desplegar su subjetividad al autoproducirse históricamente, al mismo tiempo que producen el mundo social y sus universos de sentido. En virtud de ello, se constituiría la participación de colectivos que resistan a las influencias y, por tanto, lograrían construir de manera autónoma su historia personal y la de su territorio (Zemelman, 2004).

Sugerir una cátedra de la paz que propicia la participación de todos los agentes educativos, significa hacer hincapié en la vinculación de estudiantes, maestros, directivos, padres de familia y comunidad en medio de unas relaciones horizontales y sinérgicas. Actualmente, las posturas sobre lo que debe hacer el niño, la niña y el joven para propender la paz, se han ido imponiendo desde la visión adultocéntrica, limitando en ellos su capacidad de participación. Por consiguiente, se hace preciso reconocer en ellos la legitimidad de su palabra y su mundo simbólico. Establecer espacios de diálogo permitirá no sólo la comunicación sino el reconocimiento de los estudiantes como sujetos de la vida pública.

Una cátedra de la paz transversalizada curricularmente promueve las prácticas de la "convivencia pacífica y la formación ciudadana” (Chaux y Velásquez, 2016, p.6) en todas las asignaturas, los espacios y los momentos de la cotidianidad educativa. La paz no es un "valor" que se desarrolla una vez por semana o en un proyecto trimestral, de hecho, es así como se precariza y banaliza su potencial socializador. Lamentablemente, hoy día las dinámicas educativas dificultan comprender la política y la guerra, haciéndolas un asunto inteligible para la infancia y la juventud. En varias ocasiones, les es difícil entender lo que pasa, no encuentran orientaciones hacia la vida común, ni su sentido. También, "les es difícil explicar por qué existe la violencia, por qué suben los impuestos, por qué se reelecciona a un presidente y por qué no pueden acceder al trabajo, a la salud, a la educación, a la información, a responder a sus necesidades personales en la vida cotidiana" (Alvarado, Ospina, Botero, Muñoz, 2009, p.17).

Finalmente, una cátedra de la paz como recurso para afianzar las subjetividades políticas, posibilita reconocer al niño, niña y joven como sujeto y, por lo tanto, socializador político. Concorde con Alvarado, Ospina, Botero y Muñoz (2009) los individuos cuentan con una cognición, un lenguaje, una sensibilidad, un cuerpo, unos anhelos y unas tradiciones que hacen de sí, seres históricos en construcción y de experiencia vital. Pero, a su vez, son sujetos que se dan en un «entre-nos»: en las tramas de la intersubjetividad (Martín, 2004). De ahí que, una cátedra de la paz forma sujetos plurales capaces de desplegar su subjetividad al entrar en diálogo con otros y al configurar los colectivos (Berger y Luckman, 1995; Zemelman, 2004).

A partir de lo anterior, se puede afirmar que una cátedra de la paz no se relaciona con los discursos y prácticas de los sistemas políticos formales, sino con la configuración de subjetividades, donde se reconoce a la infancia y a los jóvenes como seres inacabados en su individualidad y en su sociabilidad: en aquello que los distingue (subjetividad) y en aquello que los hace comunes e iguales (identidad) (Patiño, Alvarado \& Ospina 2014).

En este sentido, una cátedra de la paz debe propiciar las prácticas humanas desde su vivencia y narración construidas en un sentido común, así como lo menciona 
Arendt (2002): "La vida política se da siempre en el entre-nos pues la acción siempre depende de la presencia de los demás, por eso hay un vínculo entre actuar y estar juntos, y por eso la praxis requiere de la pluralidad de una comunidad que habita un espacio público". Una cátedra de la paz implica el diálogo, la negociación, el intercambio simbólico, la resistencia y la deliberación como procesos de responsabilidad social, no sólo del cumplimiento del deber. Una cátedra de la paz es el principio de toda solidaridad y de poner en marcha las múltiples opciones de ser, de estar, de decidir, de actuar y de decir como respuesta predilecta de socialización política (Patiño, Alvarado y Ospina, 2014): de nada serviría implementarla cuando se mira con desdén el matoneo que está ejerciendo un estudiante sobre otro, o cuando se permiten las riñas en los pasillos entre los propios profesores.

\section{5.- CONCLUSIÓN}

Colombia no sólo requiere hoy de los ambientes educativos, de un nuevo currículo, de la cátedra de la paz o de la influencia de los maestros en sus aulas para que se desplieguen habilidades de convivencia. Las apuestas educativas hacen parte de un vivir cotidiano desde la familia hasta los escenarios más amplios. Las apuestas educativas de transición hacia la paz se convierten en un vivir estético (Duarte, 2003) donde los niños, niñas y jóvenes se dejan tocar por el mundo hasta el punto de comprometerse con el campo de lo público. Gracias a ello, se genera la ruptura de poderes porque son ellos quienes deciden cómo aprender según su ritmo, cantidad, profundización e intereses (Tamayo, Zona, Loaiza, Yasalde, 2015) trasformando así la misión de todo maestro, de todo padre o madre, de todo educador, de todo adulto: disponer los medios.

Se requiere entonces de la conciencia colectiva para volver a mira sobre el contexto y el devenir histórico de los colombianos, así como considerar estas apuestas como una forma de interacción. Mejores ambientes educativos, un currículo contextualizado y una buena práctica de la cátedra de la paz han de propiciar la construcción de un espacio donde se configuren otros colectivos, pueblos, mundos y sociedades: "desde esta perspectiva se trata de un espacio de construcción significativa" (Duarte, 2003, p.2). Potenciar las capacidades humanas requiere traspasar el umbral de lo conocido para desarrollar el potencial creativo y dar lugar a la capacidad simbólica del mundo (Op.Cit., p.15). De esta forma, las apuestas educativas en momentos de transición hacia la paz posibilitan crearse y crear el mundo de manera responsable en medio de la libertad simbólica (Durand, 2007).

Por su parte, las preguntas fundamentales por la justicia social, la dignidad humana, la libertad, la democracia, la igualdad de oportunidades y demás asuntos de orden político-social, son resueltas en la vida cotidiana. A partir de las relaciones interpersonales y sus lenguajes se logra tomar postura y establecer lazos colectivos en búsqueda de un mejor "con-vivir» (Kemmis, 1998). Por consiguiente, la transición hacia la paz requiere de un ambiente educativo, de un currículo y de una cátedra que, en sinergia con los demás agentes educativos, logre acercarse a las realidades socioculturales y a la memoria como fuente de todo saber. Así los colombianos podrían asumirse ante el devenir de una paz sostenible. La transición requiere, además, problematizar lo que ha sucedido y lo que sucede con el fin de intervenir y realizar procesos de emancipación y emprendimiento socio-comunitarios que propicien impactos en las realidades de la sociedad actual (Tamayo, Zona, Loaiza, Yasalde, 2015).

Es responsabilidad entonces de todo educador, maestro, padre, madre, hijo, vecino, amigo y trabajador hacerse cargo de modificar el ambiente donde se desenvuelve la infancia y la juventud colombiana estableciendo relaciones que favorezcan el intercambio y las negociaciones de sentido. Un ambiente educativo, un currículo y una cátedra de la paz trascienden los escenarios formales haciéndose en una construcción dia- 
ria, en una reflexión cotidiana y en una singularidad permanente que asegura la vida en «relación-con» el otro (Ospina, 1999). Es, por tanto, misión de todo educador establecer espacios dialógicos y proyectos éticos dirigidos hacia la cultura de la paz. La misión de todo ciudadano colombiano hoy consiste en atender los escenarios de lo privado, de lo público y resignificar el posconflicto, procurando la transición hacia la paz con mejores condiciones de humanización.

\section{Referencias bibliográficas}

Alvarado, S.V., Ospina, H.F., Botero, P. y Muñoz, G. (2009). Las tramas de la subjetividad política y los desafíos a la formación ciudadana en jóvenes. Revista Argentina de Sociología 6(11), 19-43.

Apple, M. (1990). Ideology and Curriculum. New York: Routledge.

Arendt, H. (2002). Tiempos presentes. Barcelona: Gedisa.

Berger, P. \& Luckman. T. (1995). Modernidad, Pluralismo y Crisis de Sentido. Barcelona: Editorial Paidos.

Bronfenbrenner, U. (2002). La ecología del desarrollo humano. Buenos Aires: Ediciones Paidós.

Castrillón, G.A., y Cadavid, H.J. Helver Javier. (2018). Proceso de paz entre gobierno colombiano y las FARC-EP: camino hacia la reincorporación de combatientes. Entramado, 14(2) pp. 148-165 http://dx.doi. org/10.18041/1900-3803/entramado.2.4755

Casarini, M. (2019). Teoría y Diseño Curricular. México: Editorial Trillas.

Chaux, E y Velásquez, A.M. (2016). Orientaciones generales para la Implementación de la cátedra de la paz en los establecimientos educativos de preescolar, básica y media de Colombia. Bogotá: Ministerio de Educación Nacional. e: https://aprende.colombiaaprende. edu.co/ckfinder/userfiles/files/orientacionesedupaz. pdf

40 Apuestas educativas en momentos de transición hacia la paz
Congreso de la República de Colombia. (1994). Ley General de Educación. Ley 115 de 1994. https://www. mineducacion.gov.co/1621/articles-85906_archivo_ pdf.pdf

Congreso de Colombia. (2014). Ley 1732 Por la cual se establece la Cátedra de la Paz en todas las instituciones educativas del país. https://www.funcionpublica.gov. co/eva/gestornormativo/norma.php? $\mathrm{i}=59313$

Contreras, A.P. (2013). El fenómeno de bullying en Colombia. Revista Logos, Ciencia \& Tecnología, 4(2), pp. 100-1

Cubides, H. (2004). Formación del Sujeto Político. Escuela, Medios y Nuevas Tecnologías de la Comunicación y la Información en Debates sobre el Sujeto. Perspectivas Contemporáneas. Bogotá: Universidad Central -DIUN - Siglo del Hombre Editores.

Duarte, J. (2003). Ambientes Educativos una aproximación conceptual. Revista Iberoamericana de Educación. 33(1), 1-18.

Durand, G. (2007). Imaginación Simbólica. Buenos Aires: Amorrortu Editores.

Gaitán, M.C. (2018). Los propósitos del Grado de Transición: un análisis documental desde las políticas educativas colombianas [Tesis de Maestría en Educación, Pontificia Universidad Javeriana]. Repositorio Institucional Pontificia Universidad Javeriana. https://repository.javeriana.edu.co/bitstream/ handle/10554/35096/Los\%20prop\%C3\%B3sitos\%20 del\%20Grado\%20de\%20Transici\%C3\%B3n\%20 un\%20an\%C3\%A1lisis\%20documental\%20desde \%20 las\%20politicas\%20educativas\%20colombianas $\% 20$ $\% 281 \% 29 . p d f$ ? sequence $=1$ \&isAllowed $=y$

Kemmis, S. (1998). El currículum. Más allá de una teoría de la reproducción. Madrid: Ediciones MORATA.

Lévinas, E. (2014). Alteridad y Trascendencia. Barcelona: Arena Libros.

Martín, J. (2004). Crisis Identitarias y Transformacio- 
nes de la Subjetividad. En Debates sobre el Sujeto. Perspectivas Contemporáneas, Laverde, M.C., Daza, G. y Zuleta, M. Bogotá: Universidad Central - DIUN - Siglo del Hombre Editores.

Ministerio de Educación Nacional. (1997). Decreto 2247 de septiembre 11 de 1997 por el cual se establecen normas relativas a la prestación del servicio educativo del nivel preescolar y se dictan otras disposiciones. https://www.mineducacion.gov.co/1621/articles-104840_archivo_pdf.pdf

Ministerio de Educación Nacional. (2015). Decreto 1038 por el cual se reglamenta la Cátedra de la Paz. https://www.funcionpublica.gov.co/eva/gestornormativo/norma.php?i=61735

Ministerio de Educación Nacional. (2020). Pruebas saber. https://www.mineducacion.gov.co/1759/w3-article-397384.html?_noredirect $=1$

Moreno, G. y Molina, A. (1993). El ambiente Educativo. En: Planteamiento en educación.

Intervención en planteamiento de planteamientos. Bogotá: Editorial Tesaurus.

Ospina, H.F. (1999). Educar, el desafío de hoy: construyendo posibilidades y alternativas. Bogotá: Cooperativa Editorial Magisterio.

Patiño, J., Alvarado, S.V. \& Ospina, M.C. (2016). Ampliación de sentidos sobre las prácticas políticas de jóvenes con vinculación a siete movimientos sociales en Colombia. Revista latinoamericana en ciencias sociales, niñez y juventud, 12(1), 257-275. DOI: $10.11600 / 1692715 x .12115101012$

Pineda, Y. y Loaiza, Y. (2017). Un análisis del trayecto histórico del currículo en Colombia. Segunda mitad del siglo XX. Revista de Investigaciones UCM, 17(29), 150-167. DOI: http://dx.doi.org/10.22383/ri.v17i29.94

Santos Guerra, M. (2006). Currículum oculto y aprendizaje en valores. España: Guerra. Universidad de Málaga.

41 Apuestas educativas en momentos de transición hacia la paz
Tamayo, O.E., Zona, R., Loaiza, Z. \& Yasaldez E. (2015). El pensamiento crítico en la educación. Algunas categorías centrales en su estudio. Revista Latinoamericana de Estudios Educativos, 11(2), 111-133. http://vip. ucaldas.edu.co/latinoamericana/downloads/Latinoamericana11(2)_6.pdf

Salamanca, M., Rodríguez, M., Cruz, J.D., Ovalle, R., Pulido M.A. y Molano. A. (2016). Guía para la implementación de la Cátedra de la Paz. Bogotá: Santillana. https://santillanaplus.com.co/new_plus/pdf/cartillacatedra-de-paz.pdf

Valencia, O.F., Ramírez, M., y Espitia, R. (2016). Tratamiento del matoneo escolar como política pública contra la generación de violencia. [Tesis de especialización en Derecho Penal y Criminología, Universidad Libre seccional Pereira]. Repositorio Institucional Universidad Libre. https://repository. unilibre.edu.co/bitstream/handle/10901/16766/TRATAMIENTO\%20DEL\%20MATONEO\%20ESCOLAR. pdf? sequence $=1$ \&isAllowed $=y$

Zemelman, H. (2004). En torno de la Potenciación del Sujeto como Constructor de Historia en Debates sobre el Sujeto. Perspectivas Contemporáneas. Bogotá: Universidad Central - DIUN - Siglo del Hombre Editores. Zinecker, H. (2013). Aprendizaje organizacional y aprendizaje mediante la "historia como argumento" por parte de actores violentos no estatales. El caso de las FARC-EP en Colombia. Revista Análisis Político, 26(78), pp.63-89 https://revistas.unal.edu.co/index. php/anpol/article/view/43584 